\title{
In memoriam: Doctor Fernando Gilbert Quevedo Ganoza
}

\section{Querido Maestro y Amigo}

Los aquí presentes estamos junto a ti para honrar tu memoria y fundamentalmente para AGRADECER. Agradecerte Maestro por tu ejemplo de vida y probidad.

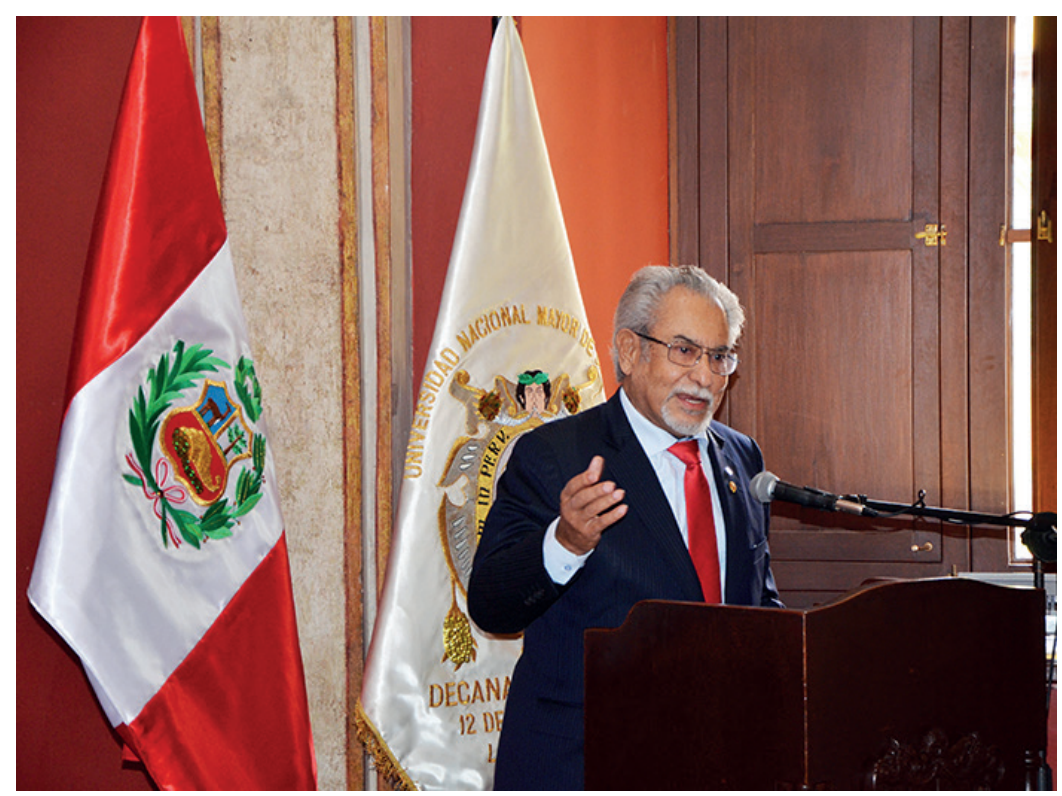

La que hidalgamente en el fecundo camino de tu vida has llevado con orgullo de hombre honesto y sencillo e inmaculada trayectoria que honran tu buen nombre y el de tu familia.

Agradecerte por tu enseñanzas no solo las del docente presente, siempre preocupado por aprender más y enseńar; sino también por la lecciones de vida, las tuyas y las que con anécdotas sin par nos transmitías a los que nos consideramos tus discípulos y amigos.

Agradecerte porque siempre nos acompañaste con una sonrisa gigante, de quien entendía que la vida estaba consagrada a dar con generosidad y a manos llenas, y que a través del disfrute de las pequeñas cosas de la vida, sencillas, pero a la vez grandes, uno encuentra el camino y el sentido de la propia existencia.

Solo recuerdo como tú mismo lo mencionas en tu discurso por el centenario del nacimiento del Maestro Juan De Dios Guevara "Cuando la Comisión Reorganizadora de San Marcos, estaba "ad portas" de hacer desaparecer la Facultad, para reducirla a una simple Escuela de la Facultad de Medicina, Juan de Dios me llamó [...], y me ordenó carińosamente con un "no todo es dinero en la vida, Profesor" que dejara un cargo internacional para el que me

\section{Citar como:}

Bravo, G. (2020). In memoriam: Doctor Fernando Gilbert Quevedo Ganoza. Ciencia e Investigación 2020 23(1):71-72. doi: http://dx.doi. org/10.15381/ci.v23i1.18755

(C) Los autores. Este artículo es publicado por la Ciencia e Investigación de la Facultad de Farmacia y Bioquímica de la Universidad Nacional Mayor de San Marcos. Este es un artículo de acceso abierto, distribuido bajo los términos de la licencia Creative Commons Atribucion - No Comercia_Compartir Igual 4.0 Internacional. (http://creativecommons.org/licenses/by-nc-sa/4.0/) que permite el uso no comercial, distribución y reproducción en cualquier medio, siempre que la obra original sea debidamente citada. 
acababan de proponer, y que regresara al Perú para evitar lo que hubiera sido una catastrófica degradación de su estatus como Facultad".

Gracias por las mil batallas que acometiste con coraje hidalgo y quijotesco por cambiar y engrandecer a tu querida facultad, nuestra profesión farmacéutica y la salud pública de nuestro país y el mundo.

Gracias por brindarnos sueños e ilusiones que se albergan en nuestros corazones que nuestra profesión y el país pueden ser siempre mejor, no sin esfuerzo, pero con una esperanza clara que esto será posible.

Padre, esposo, maestro, científico, docente, poeta, gerente, académico, orador, prosista, "sommelier", guadalupano, doctor de doctores, personalidad cosmopolita, "davinciana" y multifacética, nunca un Farmacéutico estuvo más cerca de las 7 estrellas que todo colega a nivel mundial tiene como máxima aspiración.

Y a su vez, toda esa trayectoria inigualable, que a nosotros aún con varias vidas no podríamos equiparar, llevada con una sencillez, cercanía y humanidad que pocos hombres, solo los bendecidos e iluminados pueden combinar.

En tu larga trayectoria, las medianías y mezquindades de tu tiempo, quisieron arrebatarte méritos y distinciones, pero no pudieron, porque tu grandeza de prohombre farmacéutico siempre estuvo más allá de las cortedades y envidias. Y ya nadie podrá arrebatarte el sitial que tienes entre los más grandes próceres de nuestra profesión farmacéutica Juan Luis Hague, Fortunato Carranza, Angel Maldonado, Juan de Dios Guevara y Fernando Quevedo Ganosa.

Muchas gracias, querido Maestro, por haber vivido tan ejemplarmente. A nosotros corresponde seguir tomando tu modelo como paradigma y camino de vida a seguir.

Generaciones de farmacéuticos y sanitarios que formaste e inspiraste en todo el mundo, se inclinan hoy reverentes ante tu memoria y renuevan su eterna gratitud.

Gracias a DIOS por habernos permitido conocerte y compartir contigo.

Que DIOS y tu adorada Virgen de Guadalupe te guarden en su regazo.

Amigo, hermano DESCANSA EN PAZ.

Mg. Gustavo Bravo Orellana

Discípulo 